\title{
Constraint Analysis and Bladder Wall Low-Dose-Constraint Reduction in Five-Fraction Urethra-Sparing Prostate SBRT
}

\author{
Alejandro Prado ${ }^{*}$, Inés Flores ${ }^{2}$, Ángel Montero ${ }^{3}$, Miguel Ángel de la Casa ${ }^{1}$, \\ Leyre Alonso' ${ }^{1}$ Jaime Martí1, Pedro Fernández-Letón' ${ }^{1}$, Carmen Rubio ${ }^{3}$
}

${ }^{1}$ Medical Physics and Radiation Protection Department, Hospital Universitario HM Sanchinarro, HM Hospitales, Madrid, Spain ${ }^{2}$ Medical Physics and Radiation Protection Department, Hospital General de la Defensa Gómez Ulla, Madrid, Spain

${ }^{3}$ Radiation Oncology Department, Hospital Universitario HM Sanchinarro, HM Hospitales, Madrid, Spain

Email: ^aprado@hmhospitales.com

How to cite this paper: Prado, A., Flores, I., Montero, Á., de la Casa, M.Á., Alonso, L., Martí, J., Fernández-Letón, P. and Rubio, C. (2021) Constraint Analysis and Bladder Wall Low-Dose-Constraint Reduction in FiveFraction Urethra-Sparing Prostate SBRT. International Journal of Medical Physics, Clinical Engineering and Radiation Oncology, 10, 132-148.

https://doi.org/10.4236/ijmpcero.2021.103012

Received: July 1, 2021

Accepted: August 23, 2021

Published: August 26, 2021

Copyright $\odot 2021$ by author(s) and Scientific Research Publishing Inc. This work is licensed under the Creative Commons Attribution International License (CC BY 4.0).

http://creativecommons.org/licenses/by/4.0/ (c) (i) Open Access

\begin{abstract}
Aim: To compare and analyze dose constraints and target coverage results and to reduce Bladder Wall ( $\left.B_{\text {wall }}\right) V_{18.12}$ for prostate Stereotactic-Body Radiation Therapy (SBRT) when Seminal Vesicles (SSVV) are included or not. Several indicators based on intersection volumes are obtained to predict constraint fulfillment. Background: Due to prostate's low alpha-beta ratio and the possibility of increasing the therapeutic ratio several moderate and extreme hypofractionation schemes have been proposed. The scheme selected was a fivefraction urethra-sparing prostate SBRT. Materials and Methods: 150 patients divided into two groups according to the inclusion of SSVV in PTV or not were analyzed. Histograms, average values, standard deviations and degrees of fulfillment were obtained for each constraint or goal and group. A possible reduction of the $B_{\text {wall }} V_{18.12}$ was addressed by re-optimizing fifty randomly chosen patients. Predictors of constraint fulfilling were obtained by using the intersections of $B_{\text {wall }}$ and Rectum Wall $\left(\mathrm{R}_{\text {wall }}\right)$ with the PTV. Results: Significant differences in $R_{w a l l} V_{32.62}$ and $V_{29}$ were obtained when evaluating the influence of SSVV inclusion. A reduction of $12 \%$ in the $B_{\text {wall }} V_{18.12}$ constraint was achieved without compromising coverage and OARs doses. No dependence on the inclusion of SSVV was found. Conclusions: Statistically significant differences have been found in $\mathrm{R}_{\text {wall }}$ intermediate-dose constraint when SSVV was included. A reduction of $12 \%$ in the $B_{\text {wall }} V_{18.12}$ constraint has been achieved without compromising the PTV coverage and the rest of OARs constraints. Constraint fulfillment predictors could be useful to evaluate the feasibility of prostate SBRT prior to the planning process for every single patient.
\end{abstract}


Keywords

Prostate SBRT, Urethra Sparing, Bladder Wall, Rectum Wall, Seminal Vesicles

\section{Introduction}

Prostate cancer is the most common cancer in men nowadays [1]. However, its mortality is reduced compared to other tumors such as lung cancer or colon cancer [2]. One of the main treatment options offered to patients is radiation therapy in the form of External Beam Radiation Therapy (EBRT) or Brachytherapy (BT) [3]. Although there have been no randomized trials comparing the outcomes of EBRT, BT and prostatectomy, collected data suggest that the three treatments have similar outcomes [4] [5].

External radiation therapy has the advantage of being a non-invasive technique. Moreover, conventional fractionation schemes have implied low side effects. However, the high number of fractions (over 40) has caused several logistical issues for patients [6] while supposing a considerable increase in human and economic resources. Decreasing the number of fractions has entailed a considerable benefit for patients and has increased its convenience. As a consequence, several moderate hypofractionation schemes have been proposed, with the dose per fraction ranging from 2.5 to 4 Gy [7] [8] [9] [10]. Late toxicity and freedom from biochemical failure were not statistically significant between conventional and moderate hypofractionation schemes [7] [8] [9] [10].

SBRT represents an extreme form of hypofractionation in which treatment is usually delivered in 4 - 7 fractions. Advances in radiobiological knowledge justify the use of SBRT in prostate cancer. The alpha/beta ratio is a radiobiological parameter that theoretically defines the sensitivity of each tissue to changes in treatment fractionation. Lower values of this ratio imply a higher sensitivity of the associated tissue to changes in fractionation. Evidence suggests that prostate alpha/beta ratio is nearly 1.5 Gy [11] [12] [13] [14] or even lower, which is much lower than those of neighboring tissues such as the Rectum Wall, urethra or Bladder Wall (3 - 5 Gy) [15]. These differences suggest the possibility of having a greater Biological Equivalent Dose (BED) to the tumor while improving the therapeutic ratio [16] [17], supporting extreme hypofractionated SBRT as the ideal approach [18].

Toxicity to the Rectum Wall is of major concern when designing a prostate SBRT treatment. As it is shown in [19] it is correlated with high doses to the rectum wall. Several strategies have been implemented to reduce rectum wall doses, mainly by means of planning strategies [20], by the utilization of an endorectal balloon [21] or by the insertion of prostate-rectal spacers [22] [23] [24]. Under-dosing the periurethral transition zone of the prostate may be employed to reduce the risk of urinary toxicity after radiation therapy [25] [26] [27]. With respect to bladder 
toxicity, several studies have shown that the bladder behaves like a serial organ, which implies a strong sensitivity to high doses in a reduced volume [28] [29]. In [30] a significant association of late urinary flare with dose to the hottest $12.7 \%$ of bladder volume was reported when $36.25 \mathrm{~Gy}$ in five fractions were delivered to the prostate.

Results from prostate SBRT phase II studies on large patient populations are encouraging in terms of tumor control and toxicity [31] [32] [33]. Also, several retrospectives and phase II studies have been published [34] [35] [36] [37] [38] finding encouraging results, well tolerance and excellent pathologic and biochemical control [39]. One of these trials is the Novalis Circle prospective randomized trial [33]. The constraints and fractionation used in that trial are those implemented in our work.

The main purpose of this article is to compare and analyze the dose constraint and dose goal results obtained at our center for five-fraction urethra-sparing prostate SBRT when seminal vesicles are involved or not. Two secondary objectives are also addressed. On the one hand, the relationship between volume constraints for $R_{w a l l}$ and $B_{\text {wall }}$ and the relative OAR volume inside $\mathrm{PTV}_{36.25}$. On the other hand, the possibility of significantly reducing the $\mathrm{V}_{18.12} \mathrm{~B}_{\text {wall }}$ dose constraint without compromising the coverage of the target volumes and whether this reduction depends on the inclusion of the SSVV or not.

\section{Material and Methods}

\subsection{Patient Selection}

A total of 150 patients with prostate carcinoma stage cT1-3aN0M0 treated between 2017 and 2020 at our institution were retrospectively analyzed for this study. SSVV were included in 58 patients and for the remaining 92 only whole prostate was considered. The elected patients' risk of nodal microscopic involvement was lower than $20 \%$ according to [40] allowing not considering elective pelvic nodal irradiation in any case.

\subsection{Simulation}

For each patient, a Computed Tomography (CT) simulation scan was performed. Axial slices of $2 \mathrm{~mm}$ thickness were utilized and a Toshiba Aquilion CT scanner (Canon Medical Systems, Otawara, Japan) was employed.

Five radiopaque markers placed in the patient's surface were used for localization and set up purposes when utilizing the ExacTrac imaging system (BrainLAB AG, Munich, Germany). Patients were positioned in a supine position and were immobilized using the Combifix system (Civco Radiotherapy, Coralville, Iowa).

An Endorectal Balloon (ERB) inflated with $80 \mathrm{cc}$ was employed to minimize rectum intrafraction motion and improve prostate fixation. Patients were asked to empty their bladder and drink $600 \mathrm{ml}$ of water half an hour prior to the simulation. A contrast agent was utilized to facilitate bladder contouring. Also, a Foley's catheter was introduced for accurate urethra delineation. 
Two fiducials were implanted transperineally in the prostate aided by ultrasound guidance several days prior to CT acquisition. These fiducial markers were of great importance as they were utilized as surrogates for the prostate position when oblique X-ray images were obtained.

\subsection{Contouring}

The bladder was contoured with the aid of a contrast agent. The use of an ERB helped in rectum contouring and $\mathrm{R}_{\text {wall }}$ definition. $\mathrm{R}_{\text {wall }}$ was created as a $3 \mathrm{~mm}$ thick ring centered in the rectum contour. For $B_{\text {wall }}$ a $5 \mathrm{~mm}$ thick ring centered in the bladder contour was utilized. Penile bulb and proximal femoral heads were also delineated.

The urethra was contoured using a Foley's catheter filled with a saline solution as a guide. The planning risk volume for the Urethra $\left(\mathrm{U}_{\mathrm{PRV}}\right)$ was created as an isotropic $3 \mathrm{~mm}$ expansion.

In cases where SSVV were to be treated alongside with the prostate both the prostate gland and the SSVV were contoured separately. An isotropic $5 \mathrm{~mm}$ margin was applied to the SSVV to create the PTV SSVV. Regarding prostate PTV, a 5 $\mathrm{mm}$ expansion was utilized except for the rectum direction, in which a $3 \mathrm{~mm}$ expansion was applied.

The $\mathrm{PTV}_{36.25}$ was defined as the prostate PTV or as the sum of prostate and SSVV PTVs, minus the $\mathrm{U}_{\mathrm{PRV}}$.

\subsection{Treatment Planning}

All plans were optimized using RayStation version 8A (RaySearch Laboratories, Stockholm, Sweden) utilizing a collapsed cone algorithm. Patients were treated utilizing a 6 MV Novalis (Varian Medical Systems, PA, California and BrainLAB AG, Munich, Germany) with an ExacTrac X-ray imaging system (BrainLAB AG, Munich, Germany).

The beam arrangement used was composed of four VMAT arcs. Two clockwise arcs ranging from $200^{\circ}$ to $160^{\circ}$ and two counter-clockwise arcs covering the same angle range were employed. Collimator angles were selected so as to reduce the influence of the tongue and groove effect. The chosen angles were $250^{\circ}, 290^{\circ}$, $350^{\circ}$ and $10^{\circ}$. The last two angles made the leaves travel parallel to the urethra in order to achieve a modulation that facilitated its sparing. It is worth mentioning that, for the Novalis system, a collimator angle of $0^{\circ}$ implies the leaves moving in the in-plane direction when the gantry is placed at $0^{\circ}$. The grid size for dose calculations was set to $2 \mathrm{~mm} \times 2 \mathrm{~mm} \times 2 \mathrm{~mm}$.

The OAR dose constraints used were those of the Novalis Circle Phase II prospective randomized study for low risk prostate cancer SBRT [28]. These values are summarized in Table 1.

\subsection{Data Analysis}

\subsubsection{Histogram Analysis of Constraints and Goals}

Patients were divided into two groups regarding SSVV inclusion in the $\mathrm{PTV}_{36.25}$ 
Table 1. Constraints employed for OARs and objectives por PTV 36.25 and UPRV.

\begin{tabular}{|c|c|c|}
\hline \multirow{2}{*}{ ROI } & \multicolumn{2}{|c|}{ Clinical Goals } \\
\hline & Constraints/Objectives & Value \\
\hline Femoral Heads & $\mathrm{D}_{2 \%}$ & $<18.12 \mathrm{~Gy}$ \\
\hline Penile Bulb & $\mathrm{D}_{\text {avg }}$ & $<27.2 \mathrm{~Gy}$ \\
\hline \multirow{3}{*}{ Rectum Wall } & $\mathrm{V}_{36.25}$ & $<5 \%$ \\
\hline & $\mathrm{V}_{32.62}$ & $<10 \%$ (acceptable $15 \%$ ) \\
\hline & $\mathrm{V}_{29}$ & $<20 \%$ (acceptable 25\%) \\
\hline \multirow{3}{*}{ Bladder Wall } & $\mathrm{V}_{36.25}$ & $<10 \%$ (acceptable 15\%) \\
\hline & $\mathrm{V}_{32.62}$ & $<20 \%$ \\
\hline & $\mathrm{V}_{18.12}$ & $<50 \%$ \\
\hline \multirow{4}{*}{$\mathrm{U}_{\mathrm{PRV}}$} & $\mathrm{D}_{50 \%}$ & $<32.5 \mathrm{~Gy}$ \\
\hline & $D_{98 \%}$ & $>30.87 \mathrm{~Gy}$ \\
\hline & $\mathrm{D}_{5 \%}$ & $<34.77 \mathrm{~Gy}$ \\
\hline & $\mathrm{D}_{2 \%}$ & $<35.75 \mathrm{~Gy}$ \\
\hline \multirow{3}{*}{$\mathrm{PTV}_{36.25}$} & $\mathrm{D}_{98 \%}$ & $>34.43 \mathrm{~Gy}$ \\
\hline & $\mathrm{D}_{5 \%}$ & $<38.79 \mathrm{~Gy}$ \\
\hline & $\mathrm{D}_{2 \%}$ & $<39.88 \mathrm{~Gy}$ \\
\hline
\end{tabular}

or not. OAR dose and volume constraints were recorded. Also, $\mathrm{PTV}_{36.25}$ coverage $\left(D_{98 \%}\right)$ and high doses inside the $\mathrm{PTV}_{36.25}\left(\mathrm{D}_{5 \%}\right.$ and $\left.\mathrm{D}_{2 \%}\right)$ were analyzed. For each group and constraint (or target goal) a histogram was created. To obtain the optimum number of bins for every histogram the Sturges' formula was used. As the number of patients was different depending on the inclusion of the SSVV or not the Sturges' formula provided a distinct recommended number of bins for SSVV patients and for non-SSVV patients.

Percentile curves were calculated to elucidate the degree of fulfillment for each constraint/goal. These results were recorded as percentage values.

For $\mathrm{PTV}_{36.25}, \mathrm{U}_{\mathrm{PRV}}, \mathrm{R}_{\text {wall }}$ and $\mathrm{B}_{\text {wall }}$ Dose-Volume Histogram (DVH) values were exported from the treatment planning system. A linear interpolation was performed to re-combine the histograms in a common dose grid (horizontal axis). Only when this procedure was carried out, and each OAR/target DVH had the same horizontal axis grid and range, it was possible to calculate average DVHs and 95\% Confidence Intervals (CI) for each OAR and target volume considered. It is worth mentioning that the differences between original and interpolated DVHs were estimated to be less than $0.2 \%$.

When comparing SSVV and non-SSVV groups a Mann-Whitney test was performed using a significance level of 0.05 . Hence, p-values lower than the significance level implied statistical significance.

\subsubsection{Relationships between Dose Constraints and PTV-OAR Intersections}

There would be patients which might not be eligible candidates for five-fraction urethra-sparing prostate SBRT. This is because OAR constraints are difficult or 
even impossible to achieve without a PTV underdosage. For these cases, a schedule with a higher number of fractions is recommended.

In order to prevent a repetition of the full dosimetric plan but utilizing a higher number of fractions schedule, several indicators based on $\mathrm{R}_{\text {wall }}$ and $\mathrm{B}_{\text {wall }}$ intersections with $\mathrm{PTV}_{36.25}$ are suggested. These indicators are obtained as explained below.

The intersection $\mathrm{PTV}_{36.25}-\mathrm{R}_{\text {wall }}$ and $\mathrm{PTV}_{36.25}-\mathrm{B}_{\text {wall }}$ were obtained and their volumes were calculated. Furthermore, both $\mathrm{R}_{\text {wall }}$ and $\mathrm{B}_{\text {wall }}$ volumes were recorded so as to compute their relative volume inside the $\mathrm{PTV}_{36.25}$. The differences between constraint values for $R_{w a l l}\left(V_{36.25}, V_{32.62}\right.$ and $V_{29}$, respectively) and the relative volume of its intersections with $\mathrm{PTV}_{36.25}$ were computed. The same calculations were performed for $B_{\text {wall }}$ by using the values of $V_{36.25}, V_{32.62}$ and $V_{18.12}$, respectively. This procedure was employed in both groups of patients (with and without SSVV). Average values and standard deviations were calculated.

A pre-planning simple calculation of the intersection volumes could be quite useful to both planner and radiation oncologist. These estimations of $\mathrm{R}_{\text {wall }}$ and $\mathrm{B}_{\text {wall }}$ relative volumes inside $\mathrm{PTV}_{36.25}$ can be compared with constraint values so as to estimate constraint fulfilling and evaluate the feasibility of SBRT for every single patient.

\subsubsection{Bladder Wall Low-Dose-Constraint Reduction}

Fifty patients randomly chosen among the two groups were re-planned (25 with SSVV and 25 without SSVV). The optimization was performed using the same cost function parameters as in the original plans but for the $B_{\text {wall }} V_{18.12}$ constraint, for which a new objective function was introduced. To reduce the intermediate-level dose to $B_{\text {wall, }}$ an optimization value of $\mathrm{V}_{18.12}=20 \%$ was selected. This value was considered for two main reasons: the majority of $\mathrm{V}_{18.12}$ results recorded were higher than $20 \%$ and it was a sufficiently low value to push the optimizer to reduce the $B_{\text {wall }} V_{18.12}$. Our goal was to reduce $B_{\text {wall }} V_{18.12}$ as much as possible without compromising $\mathrm{PTV}_{36.25}$ and $\mathrm{U}_{\mathrm{PRV}}$ coverage. Average differences with respect to original plans were obtained and the corresponding p-values were also computed to elucidate whether the reduction achieved in $\mathrm{V}_{18.12}$ was significant or not. A comparison between SSVV and non-SSVV results was performed to find if SSVV inclusion in $\mathrm{PTV}_{36.25}$ affected $\mathrm{V}_{18.12}$ reduction. The corresponding p-values were also obtained.

\section{Results}

\subsection{Histogram Analysis of Constraints and Goals}

Results obtained from the histograms calculated for each constraint regarding SSVV and non-SSVV groups are shown in Figure 1 and Figure 2, respectively.

For each constraint its average value, standard deviation $(\sigma)$ and the Degree Of Fulfillment (DOF) were computed (Table 2 and Table 3 ) for both SSVV and non-SSVV groups. P-values were calculated to elucidate whether there was sta- 
tistical significance or not.

The average DVH computed for $\mathrm{PTV}_{36.25}, \mathrm{R}_{\text {wall, }} \mathrm{B}_{\text {wall }}$ and $\mathrm{U}_{\mathrm{PRV}}$ over all the patients included in the SSVV and non-SSVV groups are depicted in Figure 3 and Figure 4, respectively. The 95\% Confidence Level (CL) curves alongside with the constraint/goal values for each volume are shown.

\subsection{Relationships between Dose Constraints and PTV-OAR Intersections}

Table 4 shows the average differences between the volume constraints and the relative volumes of each PTV-OAR intersection. In this case, OAR stands for both $B_{\text {wall }}$ and $R_{\text {wall }}$. The standard deviations were computed and the p-values resulting from the comparison of SSVV and non-SSVV groups data were also calculated.

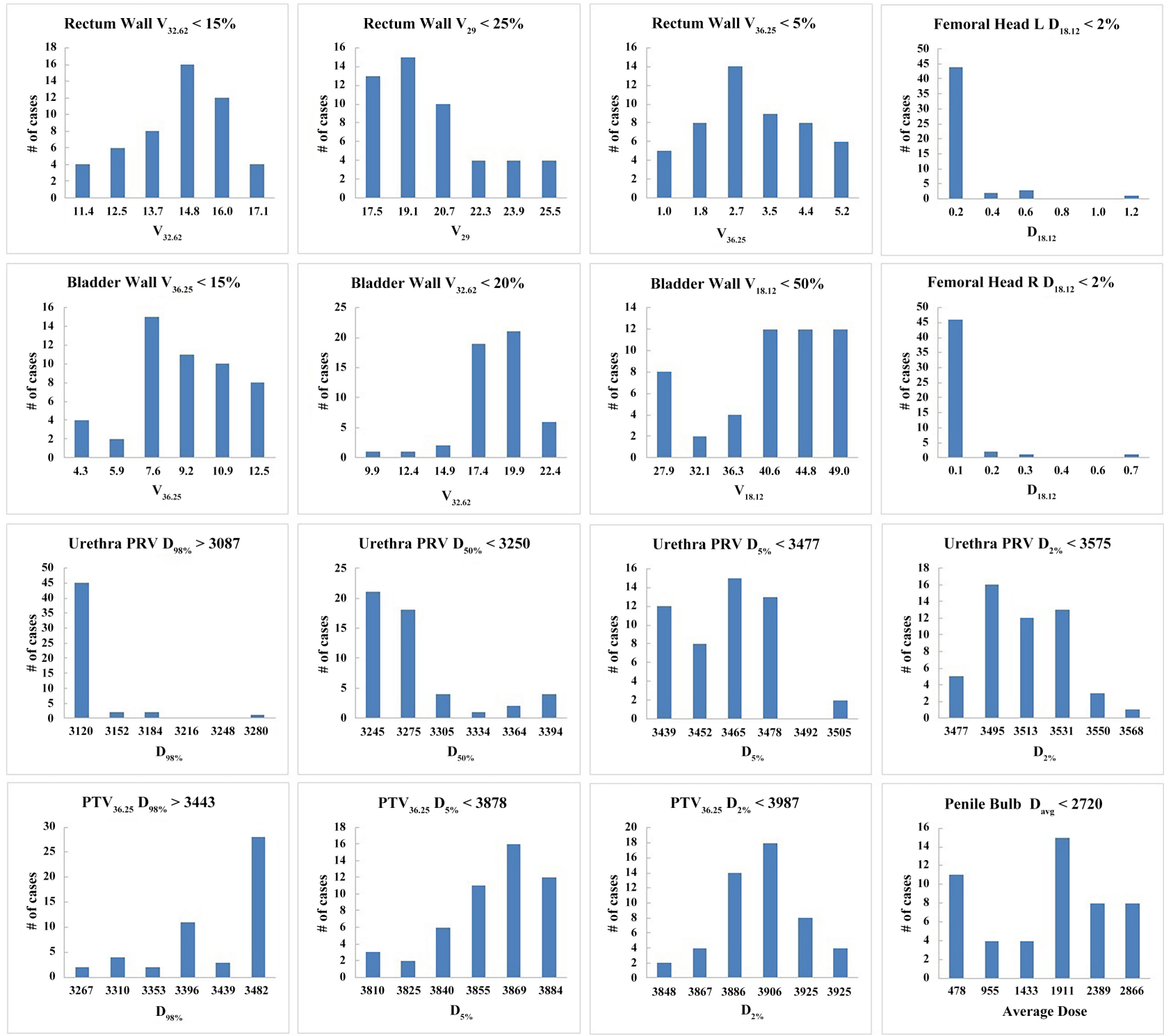

Figure 1. Constraint histograms for $\mathrm{PTV}_{36.25}$ and OARs for the SSVV group. Doses are shown in cGy. 

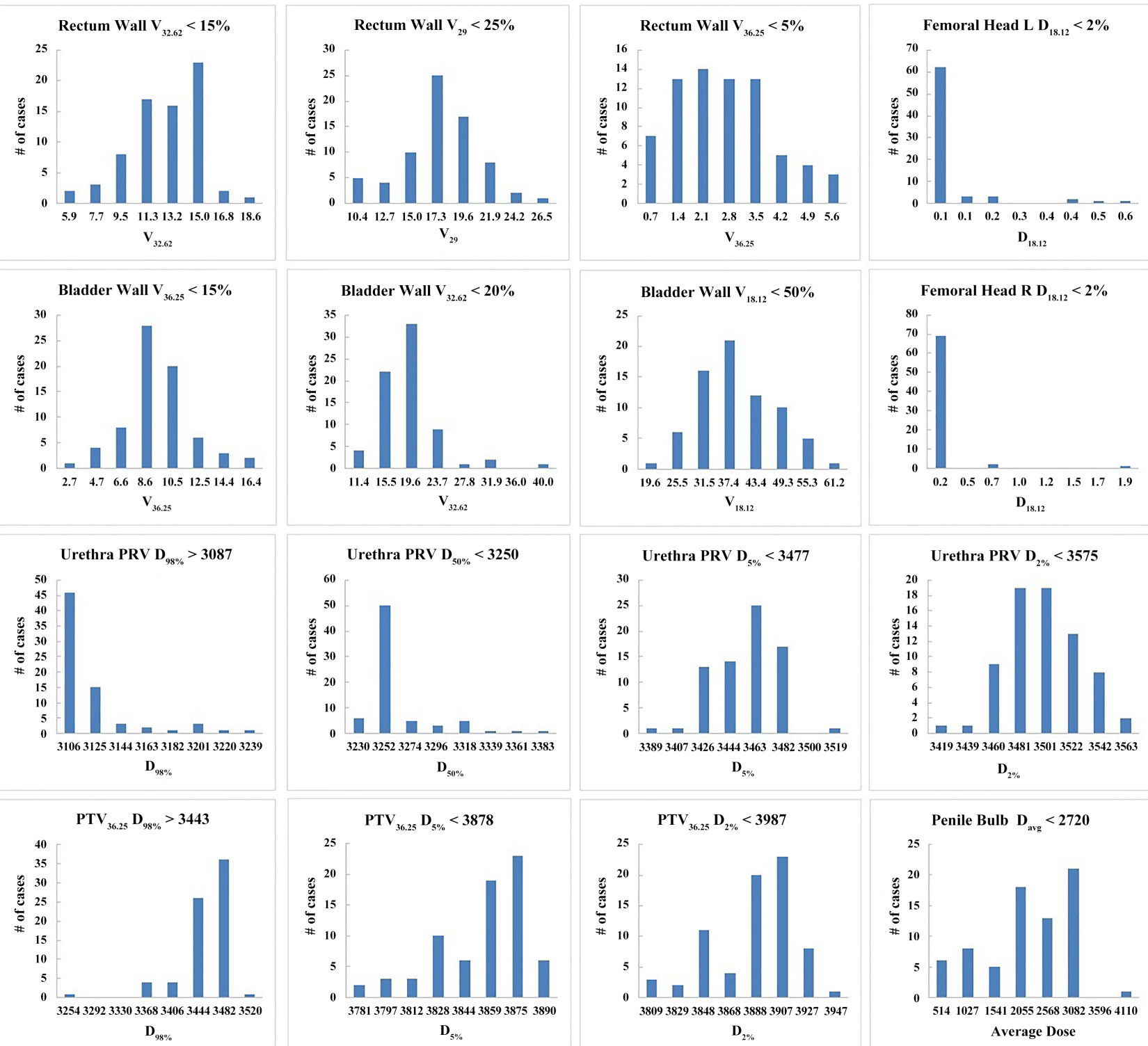

Figure 2. Constraint histograms for $\mathrm{PTV}_{36.25}$ and OARs for the non-SSVV group. Doses are shown in cGy.

Table 2. Average values, standard deviations and Degrees Of Fulfillment (DOF) for the constraints applied to $\mathrm{R}_{\text {wall }}$ and $\mathrm{B}_{\text {wall }}$ associated with SSVV and non-SSVV groups. P-values from the comparison between SSVV and non-SSVV groups are also shown.

\begin{tabular}{|c|c|c|c|c|c|c|c|c|c|c|}
\hline & & \multicolumn{5}{|c|}{ Rectum Wall } & \multicolumn{4}{|c|}{ Bladder Wall } \\
\hline & & $\mathrm{V}_{32.62}<15 \%$ & $\mathrm{~V}_{29}<25 \%$ & $\mathrm{~V}_{36.25}<5 \%$ & $\mathrm{~V}_{32.62}<10 \%$ & $\mathrm{~V}_{29}<20 \%$ & $\mathrm{~V}_{36.25}<15 \%$ & $\mathrm{~V}_{36.25}<10 \%$ & $\mathrm{~V}_{32.62}<20 \%$ & $\mathrm{~V}_{18.12<50 \%}$ \\
\hline \multirow{3}{*}{$\begin{array}{l}\text { SSVV } \\
\text { group }\end{array}$} & DOF (\%) & 77.1 & 96.1 & 100.0 & 0.0 & 67.3 & 100.0 & 81.5 & 92.7 & 100.0 \\
\hline & Average (\%) & 13.4 & 19.2 & 2.5 & 13.7 & 19.1 & 8.1 & 8.4 & 17.1 & 37.7 \\
\hline & $\sigma(\%)$ & 1.7 & 2.6 & 1.3 & 1.7 & 2.8 & 2.2 & 2.1 & 2.4 & 7.2 \\
\hline \multirow{4}{*}{$\begin{array}{c}\text { Non-SSVV } \\
\text { group }\end{array}$} & DOF (\%) & 95.8 & 100.0 & 100.0 & 25.0 & 90.0 & 100.0 & 81.9 & 87.5 & 95.8 \\
\hline & Average (\%) & 11.7 & 16.3 & 2.3 & 11.7 & 16.3 & 8.4 & 8.4 & 16.9 & 36.1 \\
\hline & $\sigma(\%)$ & 2.6 & 3.3 & 1.2 & 2.6 & 3.3 & 2.4 & 2.4 & 4.6 & 8.4 \\
\hline & $\mathrm{p}$-value & $<0.001$ & $<0.001$ & 0.120 & $<0.001$ & $<0.001$ & 0.819 & 0.819 & 0.786 & 0.132 \\
\hline
\end{tabular}


Table 3. Average values, standard deviations and Degrees Of Fulfillment (DOF) for the goals applied to PTV and UPRV associated with SSVV and non-SSVV groups. P-values from the comparison between SSVV and non-SSVV groups are also shown.

\begin{tabular}{|c|c|c|c|c|c|c|c|c|}
\hline & \multicolumn{3}{|c|}{$\mathrm{PTV}_{36.25}$} & \multicolumn{4}{|c|}{$\mathrm{U}_{\mathrm{PRV}}$} \\
\hline & & $\mathrm{D}_{98 \%}>3443$ & $\mathrm{D}_{5 \%}<3878$ & $\mathrm{D}_{2 \%}<3987$ & $\mathrm{D}_{98 \%}>3087$ & $\mathrm{D}_{50 \%}<3250$ & $\mathrm{D}_{5 \%}<3477$ & $\mathrm{D}_{2 \%}<3575$ \\
\hline \multirow{3}{*}{ SSVV group } & DOF (\%) & 44.3 & 96.1 & 100.0 & 100.0 & 58.7 & 96.5 & 100.0 \\
\hline & Average (cGy) & 3401.1 & 3853.2 & 3891.3 & 3100.8 & 3258.9 & 3456.1 & 3500.9 \\
\hline & $\sigma(\mathrm{cGy})$ & 65.1 & 20.1 & 23.0 & 32.6 & 39.0 & 19.5 & 21.7 \\
\hline \multirow{4}{*}{$\begin{array}{l}\text { Non-SSVV } \\
\text { group }\end{array}$} & DOF (\%) & 63.9 & 100.0 & 100.0 & 98.6 & 66.7 & 95.8 & 100.0 \\
\hline & Average (cGy) & 3437.1 & 3849.8 & 3877.6 & 3110.4 & 3254.2 & 3445.7 & 3488.5 \\
\hline & $\sigma(\mathrm{cGy})$ & 39.3 & 26.5 & 31.9 & 29.7 & 28.5 & 23.6 & 29.4 \\
\hline & $\mathrm{p}$-value & 0.003 & 0.078 & 0.042 & 0.320 & 0.670 & 0.034 & 0.023 \\
\hline
\end{tabular}

Table 4. Average values and standard deviations for the differences between volume constraints and PTV-OAR intersections. P-values from the comparison between SSVV and non-SSVV groups are also shown.

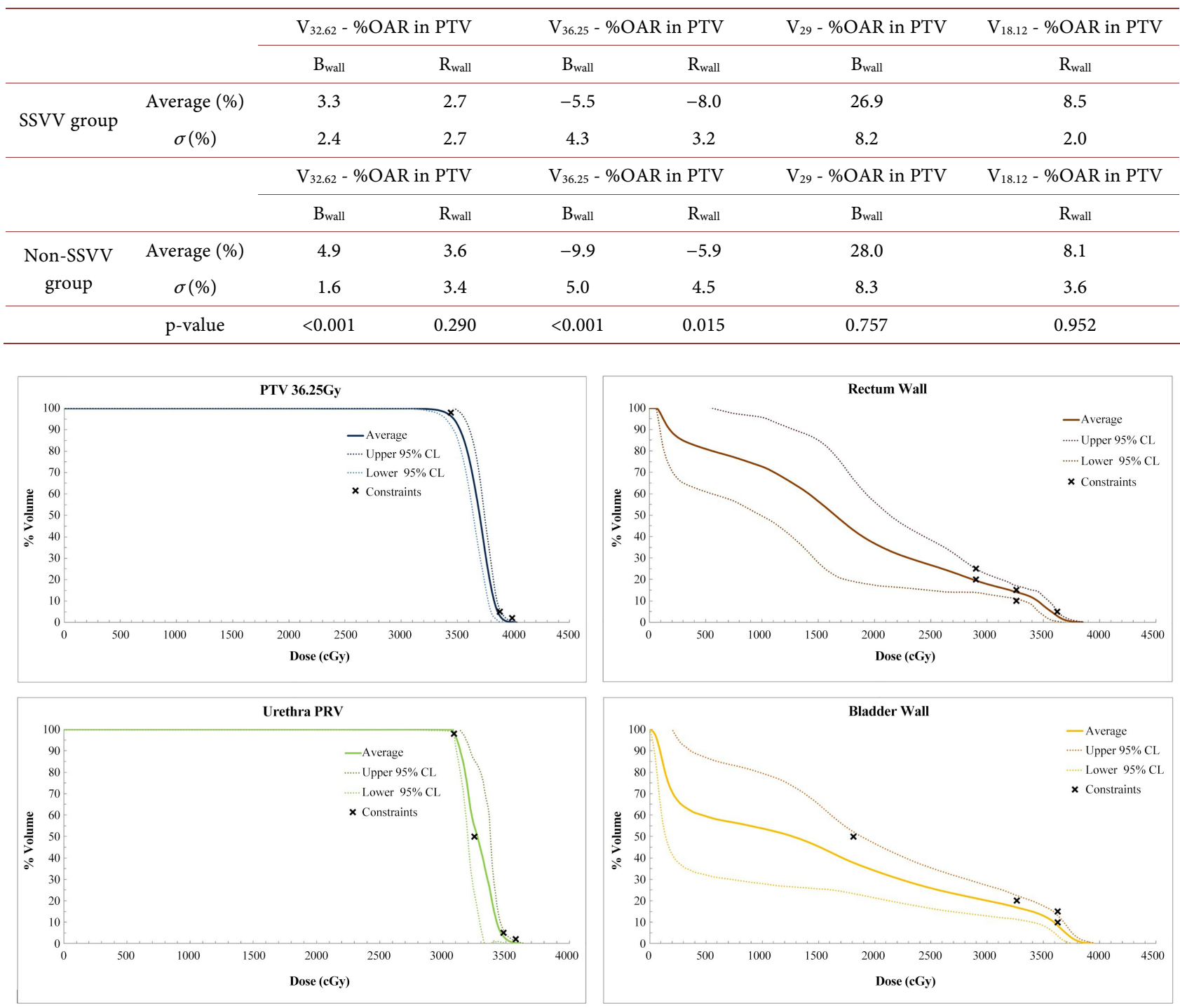

Figure 3. Average Dose-Volume Histograms (DVH) alongside with their corresponding 95\% Confidence Levels (CL) over all patients included in the SSVV group. Constraints and goals are depicted as black crosses. 

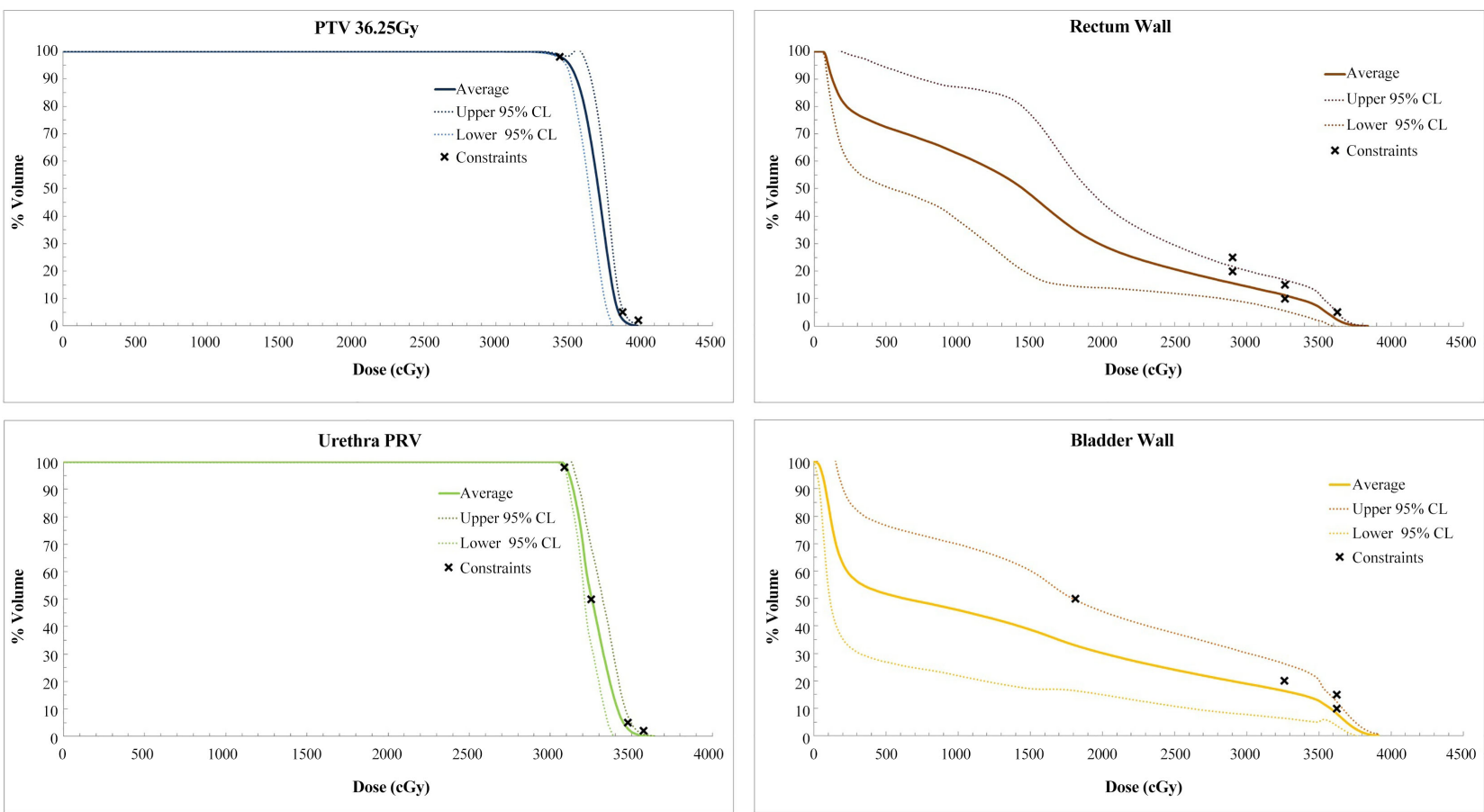

Figure 4. Average Dose-Volume Histograms with their corresponding 95\% Confidence Levels (CL) over all patients included in the non-SSVV group. Constraints and goals are depicted as black crosses.

\subsection{Bladder Wall Low-Dose-Constraint Reduction}

Average differences and standard deviations between original plan values and re-optimized plan values are shown in Table 5 (SSVV) and Table 6 (non-SSVV), respectively. Furthermore, p-values obtained from the comparison among original and re-optimized plans were also recorded.

\section{Discussion}

The inclusion of the SSVV in the PTV $\mathrm{P}_{36.25}$ significantly impacts the value of several constraints. A significant difference was obtained for $R_{\text {wall }} V_{32.62}$ and $V_{29}$ constraint values when SSVV were to be considered in the $\operatorname{PTV}_{36.25}(\mathrm{p}<0.001)$. Furthermore, the degree of fulfillment of these constraints decreased when SSVV were included. The constraint $\mathrm{V}_{32.62}<15 \%$ for non-SSVV group was achieved in 95.8\% of the cases, while a DOF of $77.1 \%$ was obtained for the SSVV group. $\mathrm{V}_{32.62}<10 \%$ was never achieved for SSVV group and a DOF of $25 \%$ was recorded for non-SSVV group. These results are related to the fact that SSVV embrace the $\mathrm{R}_{\text {wall }}$ and a larger overlap between $\mathrm{R}_{\text {wall }}$ and $\mathrm{PTV}_{36.25}$ was always generated. Besides, the use of an endorectal balloon pressed and deformed the prostate, increasing the intersection volume with the $\mathrm{R}_{\text {wall }}$. As a result, a significant increment in the average overlapping volume between $\mathrm{PTV}_{36.25}$ and $\mathrm{R}_{\text {wall }}$ was obtained ( $\mathrm{p}<$ $0.007)$, alongside with the corresponding increase of $\mathrm{V}_{32.62}$ value $(\mathrm{p}<0.001)$. The variation of $\mathrm{V}_{36.25}$ between SSVV and non-SSVV groups was not statistically significant ( $\mathrm{p}=0.12$ ), as it did not interfere with the main coverage goal for PTV $\mathrm{PV}_{36.25}$ $\left(\mathrm{D}_{98 \%}>34.43 \mathrm{~Gy}\right)$. A DOF of $100 \%$ was achieved in both groups. 
Table 5. Average values and standard deviations obtained from the differences between original plans and re-optimized plans for 25 SSVV patients. P-values are also shown.

\begin{tabular}{|c|c|c|c|c|c|c|c|}
\hline & \multicolumn{4}{|c|}{ Rectum Wall } & \multicolumn{3}{|c|}{ Bladder Wall } \\
\hline & $\mathrm{V}_{36.25}<5 \%$ & $\mathrm{~V}_{32.62}<15 \%$ & \multicolumn{2}{|c|}{$\mathrm{V}_{29}<25 \%$} & $\mathrm{~V}_{36.25}<10 \%$ & $\mathrm{~V}_{32.62}<20 \%$ & $\mathrm{~V}_{18.12}<50 \%$ \\
\hline Average difference (\%) & $-0.9 \%$ & $-0.1 \%$ & \multicolumn{2}{|c|}{$0.1 \%$} & $0.4 \%$ & $1.3 \%$ & $11.9 \%$ \\
\hline$\sigma(\%)$ & $0.9 \%$ & $0.9 \%$ & \multicolumn{2}{|c|}{$1.1 \%$} & $2.0 \%$ & $1.0 \%$ & $2.5 \%$ \\
\hline \multirow[t]{3}{*}{$\mathrm{p}$-value } & 0.524 & 0.245 & \multicolumn{2}{|c|}{0.997} & 0.918 & 0.547 & $<0.001$ \\
\hline & \multicolumn{4}{|c|}{$\mathrm{U}_{\mathrm{PRV}}$} & \multicolumn{3}{|c|}{$\mathrm{PTV}_{36.25}$} \\
\hline & $\mathrm{D}_{98 \%}>3087$ & $\mathrm{D}_{50 \%}<3250$ & $\mathrm{D}_{5 \%}<3477$ & $\mathrm{D}_{2 \%}<3575$ & $\mathrm{D}_{98 \%}>3443$ & $\mathrm{D}_{5 \%}<3878$ & $\mathrm{D}_{2 \%}<3987$ \\
\hline Average difference (cGy) & -3.0 & 0.9 & 5.1 & 3.8 & 6.3 & -8.2 & -4.5 \\
\hline$\sigma(\mathrm{cGy})$ & 8.4 & 4.9 & 36.2 & 41.7 & 23.3 & 24.1 & 24.1 \\
\hline $\mathrm{p}$-value & 0.515 & 0.244 & 0.993 & 0.776 & 0.914 & 0.558 & 0.797 \\
\hline
\end{tabular}

Table 6. Average values and standard deviations obtained from the differences between original plans and re-optimized plans for 25 non-SSVV patients. P-values are also shown.

\begin{tabular}{|c|c|c|c|c|c|c|c|}
\hline & \multicolumn{4}{|c|}{ Rectum Wall } & \multicolumn{3}{|c|}{ Bladder Wall } \\
\hline & $\mathrm{V}_{36.25}<5 \%$ & $\mathrm{~V}_{32.62}<15 \%$ & \multicolumn{2}{|c|}{$\mathrm{V}_{29}<25 \%$} & $\mathrm{~V}_{36.25}<10 \%$ & $\mathrm{~V}_{32.62}<20 \%$ & $\mathrm{~V}_{18.12}<50 \%$ \\
\hline Average difference (\%) & $-0.6 \%$ & $1.0 \%$ & \multicolumn{2}{|c|}{$1.4 \%$} & $1.1 \%$ & $2.0 \%$ & $12.0 \%$ \\
\hline$\sigma(\%)$ & $1.4 \%$ & $1.3 \%$ & \multicolumn{2}{|c|}{$1.3 \%$} & $3.0 \%$ & $2.3 \%$ & $3.3 \%$ \\
\hline \multirow[t]{3}{*}{ p-value } & 0.279 & 0.648 & \multicolumn{2}{|c|}{0.731} & 0.412 & 0.354 & $<0.001$ \\
\hline & \multicolumn{4}{|c|}{$\mathrm{U}_{\mathrm{PRV}}$} & \multicolumn{3}{|c|}{$\mathrm{PTV}_{36.25}$} \\
\hline & $\mathrm{D}_{98 \%}>3087$ & $\mathrm{D}_{50 \%}<3250$ & $\mathrm{D}_{5 \%}<3477$ & $\mathrm{D}_{2 \%}<3575$ & $\mathrm{D}_{98 \%}>3443$ & $\mathrm{D}_{5 \%}<3878$ & $\mathrm{D}_{2 \%}<3987$ \\
\hline Average difference (cGy) & 7.6 & 14.65 & -2.5 & -19.5 & -7.0 & -12.6 & -9.6 \\
\hline$\sigma(\mathrm{cGy})$ & 9.1 & 26.8 & 34.3 & 41.4 & 18.0 & 52.2 & 52.6 \\
\hline $\mathrm{p}$-value & 0.279 & 0.212 & 0.543 & 0.731 & 0.465 & 0.978 & 0.878 \\
\hline
\end{tabular}

$B_{\text {wall }}$ constraint values were not influenced by the inclusion of SSVV, as the intersection volumes with the $\mathrm{PTV}_{36.25}$ did not vary significantly among groups ( $\mathrm{p}$ $=0.13)$. $\mathrm{D}_{98 \%}$ for PTV 36.25 was slightly reduced when SSVV were to be considered $(\mathrm{p}=0.003)$. This fact may be explained due to the increased overlap between $\mathrm{R}_{\text {wall }}$ and $\mathrm{PTV}_{36.25}$. Hence, to fulfill $\mathrm{R}_{\text {wall }}$ dose constraints a loss in PTV $\mathrm{PV}_{36.25}$ coverage $\left(\mathrm{D}_{98 \%}\right)$ was needed. The DOF varied from $63.9 \%$ (non-SSVV) to $44.3 \%$ (SSVV). High doses inside the $\mathrm{PTV}_{36.25}$ were higher for SSVV group, but only $\mathrm{D}_{2 \%}$ result was statistically significant $(\mathrm{p}=0.042)$.

For the $\mathrm{U}_{\mathrm{PRV}} \mathrm{D}_{98 \%}$ and $\mathrm{D}_{50 \%}$ values did not vary significantly when SSVV were to be considered. DOF for SSVV group (non-SSVV group) were 100\% (98.6\%) and $58.7 \%(66.7 \%)$, respectively. For high doses in the $\mathrm{U}_{\mathrm{PRV}}\left(\mathrm{D}_{5 \%}\right.$ and $\left.\mathrm{D}_{2 \%}\right)$ significant differences were found ( $p=0.034$ and $p=0.023$, respectively). Higher values were obtained when SSVV were considered. Also, a high DOF for these two constraints was achieved (DOF $>95.8 \%$ ).

From Figure 3 and Figure 4, it can be seen that, while $\mathrm{PTV}_{36.25}$ and $\mathrm{U}_{\mathrm{PRV}} 95 \%$ 
CL are quite narrow, $B_{\text {wall }}$ and $R_{\text {wall }}$ ones are much broader, especially for intermediate and low dose regions. This can be explained by the effect of dose goals and dose constraints, which make the curves to move closer nearby the constrained regions. However, the 95\% CL curves broadening in unrestricted regions of the DVHs might imply the need for intermediate and low dose restrictions, which could entail a quality improvement in the dose plan.

Several authors have proposed strategies to reduce the dose to the OARs by the use of software-based techniques, i.e., dosimetry plan optimization [20] [41]. In Dubouloz et al. [41] a step-wise planning strategy was investigated for $\mathrm{R}_{\text {wall }}$ with and without an endorectal balloon. Other authors have proposed the use of gadget-based techniques to achieve this OARs dose reduction, such as the utilization of an endorectal balloon [16] or the insertion of prostate-rectal spacers [22] [23] [24].

Data shown in Table 4 may be used as a pre-planning estimation on how constraints will (or will not) be fulfilled. Calculating the relative volume of $B_{\text {wall }}$ and $\mathrm{R}_{\text {wall }}$ inside the $\mathrm{PTV}_{36.25}$ may allow the planner to compare these volumes with the results from Table 2 , hence approximately predicting the final relative volume constraint values. The average difference $\mathrm{V}_{32.62}-\mathrm{B}_{\text {wall }}$ in $\mathrm{PTV}_{36.25}$ yielded $3.3 \pm 2.4(4.9 \pm 1.6)$ for SSVV (non-SSVV) group. These values imply that the final constraint result will be approximately 3.3\% (4.9\%) higher than the intersection volume for SSVV (non-SSVV) group. It can be seen that there is a significant difference between groups $(p<0.001)$. Considering $V_{32.62}$ for $R_{w a l l}$, the obtained values were $2.7 \pm 2.7$ (3.6 \pm 3.4$)$ for SSVV (non-SSVV) group. For $\mathrm{V}_{36.25}$-OAR in $\mathrm{PTV}_{36.25}$ all obtained values were negative. This was because these intersection volumes were always higher than $R_{\text {wall }} V_{36.25}$.

Regarding intermediate dose constraint values for $B_{\text {wall }}\left(V_{18.12}\right)$ and $R_{\text {wall }}\left(V_{29}\right)$, their differences with respect to intersection volumes yielded $26.9 \pm 8.2(28.0 \pm$ $8.3)$ and $8.5 \pm 2.0(8.1 \pm 3.6)$ for SSVV (non-SSVV) group, respectively. None of them were statistically significant when comparing data from both groups. These results may be utilized as a complement criterion to decide whether a specific patient is suitable for five-fraction urethra-sparing SBRT or not, regarding constraint fulfilling. This fact might influence the subsequent clinical criterion with regard to fractionation scheme selection. As a consequence, time might be spent avoiding a full repetition of the dosimetry plan if constraints are not fulfilled.

Results obtained in the re-optimization of the selected 50 patients yielded that an average reduction of $11.9 \% \pm 2.5 \%$ (SSVV) and $12.0 \% \pm 3.3 \%$ (non-SSVV) could be achieved in the $B_{\text {wall }} V_{18.12}$ constraint $(p<0.001$ for SSVV and non-SSVV results). Besides, it could be fulfilled without compromising $\mathrm{PTV}_{36.25}$ and $U_{\mathrm{PRV}}$ coverage ( $\mathrm{p} \gg 0.05$ ). As it can be seen from Table 5 and Table 6 results, these reductions in the $B_{\text {wall }}$ intermediate dose constraint can be achieved without a statistically significant deviation not only in $\mathrm{PTV}_{36.25}$ and $\mathrm{U}_{\mathrm{PRV}}$ coverage but also in the rest of OARs constraints. A p-value $<0.001$ implied that the reduction obtained in the $B_{\text {wall }} V_{18.12}$ is independent of the inclusion of the SSVV in the $\mathrm{PTV}_{36.25}$. As it can be seen from the results, a $\mathrm{V}_{18.12}<35 \%$ constraint could 
be easily achievable in the majority of patients. Hence, it has been proposed as a new quality constraint at our institution.

Figure 1 and Figure 2 alongside with DOF obtained might be useful for institutions that want to implement prostate SBRT in order to have an estimation of constraint fulfilling, main parameter distributions and a general idea of what to expect when performing this technique. Moreover, Figure 3 and Figure 4 might be utilized as an estimation of upper and lower DVH limits for which a plan could be acceptable. Besides, Figure 3 and Figure 4 might be used as baseline DVHs to analyze whether new low-to-intermediate dose constraints implemented by other institutions could be feasible or not.

Furthermore, data recorded in Table 4 might be employed as a simple but useful predictive model for anatomies in which relative volume intersection between $\mathrm{R}_{\text {wall, }} \mathrm{B}_{\text {wall }}$ and $\mathrm{PTV}_{36.25}$ are similar or higher to $\mathrm{R}_{\text {wall }}$ and $\mathrm{B}_{\text {wall }}$ high-dose constraint values. In these cases, a decision can be made (suitability of SBRT for that specific patient) before the dosimetry plan is done. Time can be saved by avoiding a full repetition of the dose plan when fractionation schemes are changed.

\section{Conclusions}

Significant differences have been observed in the intermediate dose constraints for $R_{\text {wall }}\left(V_{32.62}\right.$ and $\left.V_{29}\right)$ when investigating SSVV inclusion in the $\mathrm{PTV}_{36.25}$. In addition, several constraint value predictors have been calculated based upon intersection volumes among $\mathrm{R}_{\text {wall, }} \mathrm{B}_{\text {wall }}$ and $\mathrm{PTV}_{36.25}$. These values may help medical physicists and radiation oncologists to precisely adapt fractionation schemes to patients by a simple pre-treatment calculation of intersection volumes and a comparison with constraint values. Furthermore, a reduction of $12 \%$ in the $B_{\text {wall }}$ $\mathrm{V}_{18.12}$ constraint has been proven to be achievable without compromising the coverage and the rest of OARs constraints. Moreover, this reduction is independent of the inclusion or not of the SSVV in the PTV $\mathrm{P}_{36.25}$. Based on the ALARA principle (As Low As Reasonably Achievable) further investigation is encouraged to define low-to-intermediate new dose constraints which would aid to improve the dosimetric plan quality for prostate SBRT patients.

As a final remark, this paper might be useful for institutions to start performing five-fraction urethra-sparing prostate SBRT and for experienced planners who might be searching for new tips to improve their treatment plans.

\section{Conflicts of Interest}

The authors declare no conflicts of interest regarding the publication of this paper.

\section{References}

[1] Siegel, R.L., Miller, K.D. and Jemal, A. (2020) Cancer Statistics, 2020. CA: A Cancer Journal for Clinicians, 70, 7-30. https://doi.org/10.3322/caac.21590

[2] National Cancer Institute (2021) Cancer Stat Facts: Cancer of Any Site: Number of 
New Cases and Deaths. https://seer.cancer.gov/statfacts/html/all.html

[3] Schaeffer, E., et al. (2021) NCCN Guidelines Insights: Prostate Cancer, Version 1.2021. Official Journal of the National Comprehensive Cancer Network. 19, 134-143. https://doi.org/10.6004/jnccn.2021.0008

[4] Kishan, A.U., Karnes, R.J., Romero, T., Wong, J.K., Motterle, G., Tosoian, J.J., et al. (2021) Comparison of Multimodal Therapiues and Outcomes among Patients with High-Risk Prostate Cancer with Adverse Clinicopathologic Features. JAMA Neteork Open, 4, Article No. e2115312. https://doi.org/10.1001/jamanetworkopen.2021.15312

[5] Kupelian, P.A., Potters, L., Khuntia, D., Ciezki, J.P., Reddy, C.A., Reuther, A.M., Carlson, T.P. and Klein, E.A. (2004) Radical Prostatectomy, External Beam Radiotherapy<72Gy, External Beam Radiotherapy $\geq 72$ Gy, Permanent Seed Implantation, or Combined Seeds/External Beam Radiotherapy for Stage T1-T2 Prostate Cancer. International Journal of Radiation Oncology, Biology, Physics, 58, 25-33. https://doi.org/10.1016/S0360-3016(03)00784-3

[6] Dandapani, S.V. and Sanda, M.G. (2008) Measuring Health-Related Quality of Life Consequences from Primary Treatment for Early-Stage Prostate Cancer. Seminars in Radiation Oncology, 18, 67-72. https://doi.org/10.1016/j.semradonc.2007.10.001

[7] Kupelian, P.A., Willoughby, T.R., Reddy, C.A., Klein, E.A. and Mahadevan, A. (2007) Hypofractionated Intensity-Modulated Radio-Therapy (70 Gy at 2.5 Gy per Fraction) for Localized Prostate Cancer: Cleveland Clinic Experience. International Journal of Radiation Oncology, Biology, Physics, 68, 1424-1430.

https://doi.org/10.1016/j.ijrobp.2007.01.067

[8] Yeoh, E.E., Holloway, R.H., Fraser, R.J., Botten, R.J., Matteo, A.C.D., Butters, J., Weerasinghe, S. and Abeysinghe, P. (2006) Hypofractionated versus Conventionally Fractionated Radiation Therapy for Prostate Carcinoma: Updated Results of a Phase III Randomized Trial. International Journal of Radiation Oncology, Biology, Physics, 66, 1072-1083. https://doi.org/10.1016/j.ijrobp.2006.06.005

[9] Pollack, A., Walker, G., Horowitz, E.M., Price, R., Feigenberg, S., Konski, A.A., Movsas, B. (2013) Randomized Trial of Hypofractionated External Beam Radiotherapy for Prostate Cancer. Journal of Clinical Oncology, 31, 3860-3868.

https://doi.org/10.1200/JCO.2013.51.1972

[10] Arcangeli, A., Saracino, B., Gomellini, S., Petrongari, M.G., Arcangeli, S., Sentinelli, S., Marzi, S., Landoni, V., Fowler, J. and Strigari, L. (2010) A Prospective Phase III Randomized Trial of Hypofractionation versus Conventional Fractionation in $\mathrm{Pa}$ tients with High Risk Prostate Cáncer. International Journal of Radiation Oncology, Biology, Physics, 78, 11-18. https://doi.org/10.1016/j.ijrobp.2009.07.1691

[11] Fowler, J.F., Toma-Dasu, J. and Dasu, A. (2013) Is the Alpha-Beta Ratio for Prostate Tumors Really Low and Does it Vary with the Level of Risk at diagnosis? Anticancer Research, 33, 1009-1011.

[12] Vogelius, I.R. and Bentzen, S.M. (2013) Meta-Analysis of the Alpha/Beta Ratio for Prostate Cancer in the Presence of an Overall Time Factor: Bad News, Good News, or No News? International Journal of Radiation Oncology, Biology, Physics, 85, 89-94. https://doi.org/10.1016/j.ijrobp.2012.03.004

[13] Vogelius, I.R. and Bentzen, S.M. (2018) Dose Response and Fractionation Sensitivity of Prostate Cancer after External Beam Radiation Therapy: A Meta-Analysis of Randomized Trials. International Journal of Radiation Oncology, Biology, Physics, 100, 858-865. https://doi.org/10.1016/j.ijrobp.2017.12.011

[14] van Leeuwen, C.M., Oei, A.L., Crezee, J., Bel, A., Franken, N.A.P., Stalpers, L.J.A. and 
Kok, H.P. (2018) The Alfa and Beta of Tumours: A Review of Parameters of The Linear-Quadratic Model, Derived From Clinical Radiotherapy Studies. Radiation Oncology, 13, Article No. 96. https://doi.org/10.1186/s13014-018-1040-Z

[15] Avkshtol, V., Dong, Y., Hayes, S.B., Hallman, M., Price, R., Sobczak, M., Horwitz, E. and Zaorsky, N. (2016) A Comparison of Robotic Arm versus Gantry Linear Accelerator Stereotactic Body Radiation Therapy for Prostate Cancer. Research and Reports in Urology, 8, 145-148. https://doi.org/10.2147/RRU.S58262

[16] Zaorsky, N.G., Harrison, A.S., Trabulsi, E.J., Gomella, L.G., Showalter, T.N., Hurwitz, M.D., Dicker, A.P. and Den, R.B. (2013) Evolution of Advanced Technologies in Prostate Cancer Radiotherapy. Nature Reviews Urology, 10, 565-579. https://doi.org/10.1038/nrurol.2013.185

[17] Kim, D.N., Straka, C., Cho, L.C., Lotan, Y., Yan, J., Kavanagh, B., Raben, D., Cooley, S., Brindle, J., Xie, X.J., Pistenmaa, D. and Timmerman, R. (2017) Early and Multiple PSA Bounces Can Occur Following High-Dose Prostate Stereotactic Body Radiation Therapy: Subset Analysis of a Phase 1/2 Trial. Practical Radiation Oncology, 7, e43-e49. https://doi.org/10.1016/j.prro.2016.06.010

[18] Jackson, W.C., Silva, J., Hartman, H.E., et al. (2019) Stereotactic Body Radiation Therapy for Localized Prostate Cancer: A Systematic Review and Meta-Analysis of Over 6,000 Patients Treated on Prospective Studies. International Journal of Radiation Oncology, Biology, Physics, 104, 778-789.

https://doi.org/10.1016/j.ijrobp.2019.03.051

[19] Kim, D.W., Cho, L.C., Straka, C., Christie, A., Lotan, Y., Pistenmaa, D., Kavanagh, B.D., Nanda, A., Kueplian, P., Brindle, J., Cooley, S., Perkins, A., Raben, D., Xie, X.-J. and Timmerman, R.D. (2014) Predictors of Rectal Tolerance Observed in a Dose-Escalated Phase 1-2 Trial Of Stereotactic Body Radiation Therapy for Prostate Cancer. International Journal of Radiation Oncology, Biology, Physics, 89, 509-517. https://doi.org/10.1016/j.ijrobp.2014.03.012

[20] Serra, M., Ametrano, G., Borzillo, V., Quarto, M., Muto, M., Franco, R.D., Savino, F., Filomena, L. and Muto, P. (2020) Dosimetric Comparison among Cyberknife, Helical Tomotherapy and VMAT for Hypofractionated Treatment in Localized Prostate Cancer. Medicine, 99, Article No. e23574.

https://doi.org/10.1097/MD.0000000000023574

[21] Smeenk, R.J., The, B.S., Butler, E.B., van Lin, E.N. and Kaanders, J.H. (2010) Is There a Role for Endorectal Balloons in Prostate Radiotherapy? A Systematic Review. Radiotherapy and Oncology, 95, 277-282. https://doi.org/10.1016/j.radonc.2010.04.016

[22] Chapet, O., Udrescu, C., Devonec, M., Tanguy, R., Sotton, M.-P., Enachescu, C., et al. (2013) Prostate Hypofractionated Radiation Therapy: Injection of Hyaluronic Acid to Better Preserve the Rectal Wall. International Journal of Radiation Oncology, Biology, Physics, 86, 72-76. https://doi.org/10.1016/j.ijrobp.2012.11.027

[23] Weber, D.C., Zilli, T., Vallee, J.P., Rouzaud, M., Miralbell, R. and Cozzi, L. (2012) Intensity Modulated Proton and Photon Therapy for Early Prostate Cancer with or without Transperineal Injection of a Polyethylene Glycol Spacer: A Treatment Planning Comparison Study. International Journal of Radiation Oncology, Biology, Physics, 84, S357, 2370. https://doi.org/10.1016/j.ijrobp.2012.07.942

[24] Isacsson, U., Nilsson, K., Asplund, S., Morhed, E., Montelius, A. and Turesson, I. (2010) A Method to Separate the Rectum from the Prostate during Proton Beam Radiotherapy of Prostate Cancer Patients. Acta Oncologica, 49, 500-505. https://doi.org/10.3109/02841861003745535

[25] Shimizu, S., Nishioka, K., Suzuki, R., Shinohara, N., Maruyama, S., Abe, T., et al. (2014) Early Results of Urethral Dose Reduction and Small Safety Margin in Intensity-Modulated Radiation Therapy (IMRT) for Localized Prostate Cancer Using a 
Real-Time Tumor-Tracking Radiotherapy (RTRT) System. Radiation Oncology, 9, Article No. 118. https://doi.org/10.1186/1748-717X-9-118

[26] Chen, L.N., Suy, S., Uhm, S., Oermann, E.K., Ju, A.W., Chen, V., et al. (2013) Stereotactic Body Radiation Therapy (SBRT) for Clinically Localized Prostate Cancer: The Georgetown University Experience. Radiation Oncology, 8, Article No. 58. https://doi.org/10.1186/1748-717X-8-58

[27] Vainshtein, J., Abu-Isa, E., Olson, K.B., Ray, M.E., Sandler, H.M, Normolle, D., et al. (2012) Randomized Phase II Trial of Urethral Sparing Intensity Modulated Radiation Therapy in Low-Risk Prostate Cancer: Implications for Focal Therapy. Radiation Oncology, 7, Article No. 82. https://doi.org/10.1186/1748-717X-7-82

[28] Harsolia, A., Vargas, C., Yan, D., Brabbins, D., Lockman, D., Liang, J., et al. (2007) Predictors for Chronic Urinary Toxicity after the Treatment of Prostate Cancer with Adaptive Three-Dimensional Conformal Radiotherapy: Dose-Volume Analysis of a Phase II Dose-Escalation Study. International Journal of Radiation Oncology, Biology, Physics, 69, 1100-1109. https://doi.org/10.1016/j.ijrobp.2007.04.076

[29] Ghadjar, P., Zelefsky, M.J., Spratt, D.E., Munck af Rosenschöld, P., Oh, J.H., Hunt, Ma., et al. (2014) Impact of Dose to the Bladder Trigone on Long-Term Urinary Function after High-Dose Intensity Modulated Radiation Therapy for Localized Prostate Cancer. International Journal of Radiation Oncology, Biology, Physics, 88, 339-344. https://doi.org/10.1016/j.ijrobp.2013.10.042

[30] Kole, T.P., Tong, M., Wu, B., Lei, S., Obayomi, O., Chen, L.N., et al. (2016) Late Urinary Toxicity Modeling after Stereotactic Body Radiotherapy (SBRT) in the Definitive Treatment of Localized Prostate Cancer. Acta Oncologica, 55, 52-58. https://doi.org/10.3109/0284186X.2015.1037011

[31] King, C.R., Freeman, D., Kaplan, I., Fuller, D., Bolzicco, G., Collins, S., et al. (2013) Stereotactic Body Radiotherapy for Localized Prostate Cancer: Pooled Analysis from a Multi-Institutional Consortium of Prospective Phase II Trials. Radiotherapy and Oncology, 109, 217-221. https://doi.org/10.1016/j.radonc.2013.08.030

[32] King, C.R., Collins, S., Fuller, D., Wang, P.C., Kupelian, P., Steinberg, M., et al. (2013) Health-Related Quality of Life after Stereotactic Body Radiation Therapy for Localized Prostate Cancer: Results from a Multi-Institutional Consortium of Prospective Trials. International Journal of Radiation Oncology, Biology, Physics, 87, 939-945. https://doi.org/10.1016/j.ijrobp.2013.08.019

[33] Miralbell, R., et al. (2014) Stereotactic Body Radiotherapy for CT1c-CT3a Prostate Cancer with a Low Risk of Nodal Metastases (<20\%, Roach Index): A Novalis Circle Phase II Prospective Randomized Trial. ClinicalTrials.gov Identifier NCT01764646.

[34] Katz, A.J. and Kang, J. (2014) Stereotactic Body Radiotherapy as Treatment for Organ Confined Low- and Intermediate Risk Prostate Carcinoma: A 7-Year Study. Frontiers in Oncology, 4, Article No. 240. https://doi.org/10.3389/fonc.2014.00240

[35] Meier, R., Beckman, A., Henning, G., Mohideen, N., Woodhouse, S.A., Cotrutz, C. et al. (2016) Five-Year Outcomes from a Multicenter Trial of Stereotactic Body Radiation Therapy for Low-and-Intermediate-Risk Prostate Cancer. International Journal of Radiation Oncology, Biology, Physics, 96, S33-S34. https://doi.org/10.1016/j.ijrobp.2016.06.094

[36] Mantz, C. (2014) A Phase II Trial of Stereotactic Ablative Body Radiotherapy for Low-Risk Prostate Cancer Using a Non-Robotic Linear Accelerator and Real Time Target Tracking: Report of Toxicity, Quality of Life and Disease Control Outcomes with 5-Year Minimum Follow-Up. Frontiers in Oncology, 4, Article No. 279. https://doi.org/10.3389/fonc.2014.00279

[37] Brand, D.H., Tree, A.C., Ostler, P., van der Voet, H., Loblaw, A., Chu, W., Raben, D., 
Nanda, A., Cooley, S., Kim, D.W.N., Pistenmaa, D., Lotan, Y. and Timmerman, R. (2019) Intensity-Modulated Fractionated Radiotherapy versus Stereotactic Body Radiotherapy for Prostate Cancer (PACE-B): Acute Toxicity Findings from an International, Randomized, Open-Label, Phase III, Non-Inferiority Trial. The Lancet Oncology, 20, 1531-1543. https://doi.org/10.1016/S1470-2045(19)30569-8

[38] Hannan, R., Tumati, V., Xie, X.J., Cho, L.C., Kavanagh, B.D., Brindle, J., et al. (2016) Stereotactic Body Radiation Therapy for Low and Intermediate Risk Prostate Cancer: Results from a Multi-Institutional Clinical Trial. European Journal of Cancer, 59, 142-151. https://doi.org/10.1016/j.ejca.2016.02.014

[39] Loblaw, A., Cheung, P., D’Alimonte, L., Deabreu, A., Mamedov, A., Zhang, L., et al. (2013) Prostate Stereotactic Ablative Body Radiotherapy Using a Standard Linear Accelerator: Toxicity, Biochemical and Pathological Outcomes. Radiotherapy and Oncology, 107, 153-158. https://doi.org/10.1016/j.radonc.2013.03.022

[40] Roach III, M., Marquez, C., Yuo, H.S., Narayan, P., Coleman, L., Nseyo, U.O., et al. (1994) Predicting the Risk of Lymph Node Involvement Using the Pre-Treatment Prostate Specific Antigen and Gleason Score in Men with Clinically Localized Prostate Cancer. International Journal of Radiation Oncology, Biology, Physics, 28, 33-37. https://doi.org/10.1016/0360-3016(94)90138-4

[41] Dubouloz, A., Rouzaud, M., Tsvang, L., Verbakel, W., Björkqvist, M., Linthout, N., Lencart, J., Pérez-Moreno, J.M., Ozen, Z., Escude, L., Zilli, T. and Miralbell, R. (2018) Urethra-Sparing Stereotactic Body Radiotherapy for Prostate Cancer: How Much Can the Rectal Wall Dose Be Reduced with or without an Endorectal Balloon? Radiation Oncology, 13, Article No. 114. https://doi.org/10.1186/s13014-018-1059-1 